\title{
Potential effects of changes in mean climate and climate variability on the yield of winter and spring crops in Switzerland
}

\author{
Daniele Simone Torriani ${ }^{1,2}$, Pierluigi Calanca ${ }^{1, *}$, Stéphanie Schmid $^{1}$, \\ Martin Beniston' ${ }^{2}$, Jürg Fuhrer ${ }^{1}$
}

\author{
${ }^{1}$ Air Pollution/Climate Group, Agroscope Reckenholz-Taenikon, Research Station ART, 8046 Zurich, Switzerland \\ ${ }^{2}$ Climate Research, University of Geneva, 7 Chemin de Drize, 1227 Carouge, Switzerland
}

\begin{abstract}
Climate change is expected to affect both the average level and the variability of crop yields. In this modelling study, we quantified mean and inter-annual variability of grain yield for maize Zea mays L., winter wheat Triticum spp. L. and winter canola Brassica napus L. for climatic conditions corresponding to current and doubled atmospheric $\mathrm{CO}_{2}$ concentrations. Climate scenarios with and without taking into account changes in the inter-annual variability of climate were developed from the output of a regional climate model for the time window 2071 to 2100 . Climate change effects on the mean yield of maize and canola were consistently negative, but a positive impact was simulated for mean yield of winter wheat for elevated $\mathrm{CO}_{2}$ concentration. The coefficient of yield variation increased in the scenarios for maize and canola, but decreased for wheat. Higher thermal time requirements increased mean yield and reduced yield variability for all crops. Shifts in the sowing dates had a beneficial impact on the yield of maize, but not on the yield of canola and wheat. It is concluded that in the Alpine region, the potential effect of climate change is crop-specific. However, the introduction of new cultivars may provide means by which to maintain or even increase current productivity levels for most of the crops.
\end{abstract}

KEY WORDS: Climate change $\cdot$ Climate scenario $\cdot$ Inter-annual variability $\cdot$ Crop yield $\cdot$ Maize Winter wheat $\cdot$ Winter canola

\section{INTRODUCTION}

The stability of crop yield is of great importance for farmers, food markets and political advisors, because large year-to-year variations in crop yield constrain overall farm productivity and farmers' net benefits (Sombroek \& Bazzaz 1996). Using worldwide data, Calderini \& Slafer (1998) found that during the 20th century the yield stability of wheat increased in 7 countries but decreased in 14. In many European countries, the yield stability of several crops increased in recent years (Chloupek et al. 2004), but the opposite was observed in the USA, possibly as a consequence of increasing climate variability (Rosenzweig \& Iglesias 2000).
Inter-annual variability of crop yield is affected by many factors, including improvements in the production practices, the appearance of new diseases and pests, changes in governmental policies, and differences in the climate settings from year to year. Experiments with climate models suggest that the latter could be enhanced by global warming (Räisänen 2002). For Europe, regional scenarios in particular indicate an increase in the variability of summer climate and a more frequent appearance of summer heat waves (Beniston \& Diaz 2004).

For many years, the implications of changes in climate variability for the productivity of crops have received less attention than the effects of a steady 
increase in mean temperature. Enhanced climate variability may lower mean yields because of a higher incidence of years with adverse conditions (Southworth et al. 2000), but sign and magnitude of the impacts will likely vary from region to region and depend on the crop (Porter \& Semenov 2005). In Europe, productivity is likely to increase in northern Europe but decrease in southern Europe, unless adaptive measures are implemented to cope with the negative impact of climate change (Olesen \& Bindi 2002).

The specific response of crops to climate change will depend on how growth and yield formation are stimulated by elevated $\mathrm{CO}_{2}$ concentrations. Direct stimulation of photosynthesis and increase in transpiration and water use efficiencies both play a role (Fuhrer 2003). The potential for a direct effect is larger in C3 than C4 crops, because ribulose-1,5-bisphosphate carboxylaseoxygenase ( $\mathrm{RuBisCO}$ ) in the latter is already $\mathrm{CO}_{2}$ saturated at current atmospheric levels (Long et al. 2004).

The overall objective of our study was to examine the effects of climate change on productivity for 3 of the main crops grown in Switzerland and Europe, namely Zea mays L. (maize), a C4 crop, Triticum spp. L. (winter wheat) and Brassica napus L. (winter canola), both C3 crops. Specific aims were to (1) develop a climate change scenario that accounts not only for the change in mean conditions but also in year-to-year variability; (2) compare mean yield levels and yield variability under current and projected future climatic conditions based on the results of simulations with a processbased crop model; and (3) test the sensitivity of yield and yield variability to changes in the thermal requirements and shifts in sowing date.

\section{CLIMATIC DATA AND PROJECTIONS}

The source of climatic data was the monitoring network of the Swiss Federal Office of Meteorology and Climatology (MeteoSwiss, www.meteoswiss.ch). For our study we considered daily weather data covering the period of 1981 to 2003 for a representative location on the Swiss Plateau (Waedenswil, WAE, $\left.47^{\circ} 26^{\prime} \mathrm{N}, 8^{\circ} 31^{\prime} \mathrm{E}\right)$. Additional stations were used to carry out model calibration and testing: these are referenced in Section 3 and reported in Fig. 1.

As in Beniston \& Diaz (2004), results of simulations carried out by the Danish Meteorological Institute with the regional climate model HIRHAM4 (Christensen et al. 1998) were used to infer climate projections for WAE for the nominal time window of 2071 to 2093. The original data are available from the homepage of the PRUDENCE initiative (http://prudence.dmi.dk, Christensen et al. 2002) and include a control run valid for 1961 to 1990 and a climate scenario valid for 2071 to

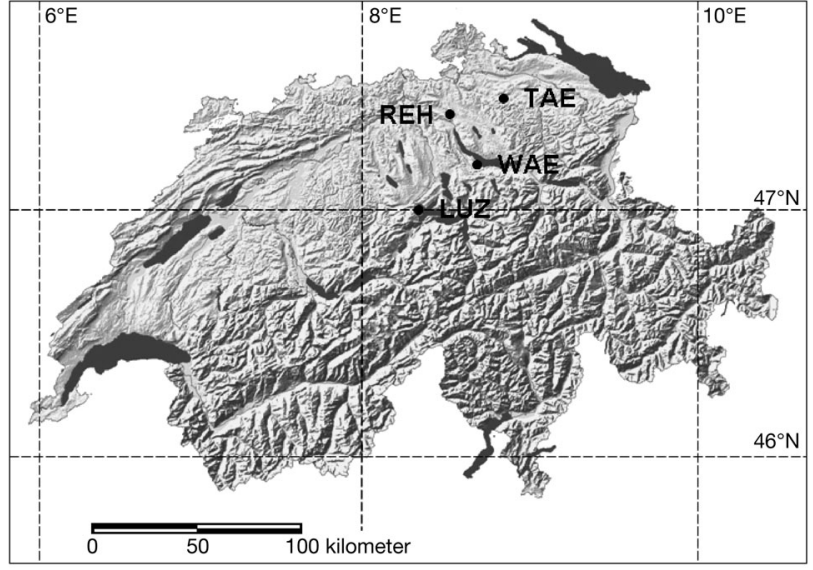

Fig. 1. Location of meteorological stations in Switzerland: Lucerne (LUZ, $\left.47^{\circ} 0^{\prime} \mathrm{N}, 8^{\circ} 30^{\prime} \mathrm{E}\right)$, Taenikon (TAE, $47^{\circ} 29^{\prime} \mathrm{N}$, $8^{\circ} 54^{\prime} \mathrm{E}$ ), Waedenswil (WAE, $47^{\circ} 26^{\prime} \mathrm{N}, 8^{\circ} 31^{\prime} \mathrm{E}$ ) and ZurichReckenholz (REH, $\left.47^{\circ} 26^{\prime} \mathrm{N}, 08^{\circ} 31^{\prime} \mathrm{E}\right)$

2100. The emission scenario adopted for this specific experiment was the IPCC SRES A2 scenario (Nakicenovic \& Swart 2000). The corresponding $\mathrm{CO}_{2}$ level was about 800 ppmv by 2100 (3 times the pre-industrial values), which provided an upper bound for the ensemble of projections discussed in the Third Assessment Report of the IPCC (Houghton et al. 2001).

Initial and boundary conditions for running HIRHAM4 were inferred from simulations conducted by the UK Hadley Centre with the high-resolution atmospheric circulation model HadAM3H (Pope et al. 2000). The latter were driven with the output of the fully coupled ocean-atmosphere global climate model HadCM3 (Johns et al. 2003).

The grid-point with coordinates $47^{\circ} 15^{\prime} \mathrm{N}, 8^{\circ} 35^{\prime} \mathrm{E}$ situated $608.98 \mathrm{~m}$ above sea level was adopted to represent WAE, and specific climate scenarios were constructed by applying monthly climate anomalies modelled by HIRHAM4 for this grid-point as adjustments to the daily observations. We considered absolute changes for temperature and air humidity, but relative changes for precipitation and solar radiation. Two approaches were followed:

(1) CM approach. Here we used constant anomalies, accounting only for changes in the long-term mean climate. This is analogue to the procedure followed in many impact studies (e.g. Jasper et al. 2004), but has the drawback of arbitrarily distorting the inter-annual SD (Mearns et al. 1997).

(2) CC approach. According to the results of the HIRHAM4 simulations, changes in climate from year to year can be considerable. This is best seen in plots of the probability density functions of monthly values (Fig. 2). For this reason, in the second approach monthly anomalies were calculated for each year 


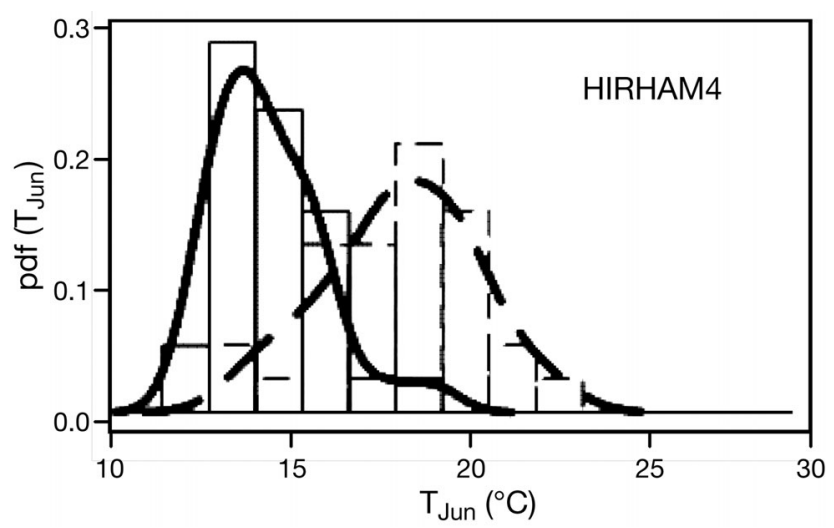

Fig. 2. Histogram and fitted probability density function (pdf) for June monthly mean temperature simulated by HIRHAM4 in the control (solid lines) and 2071-2100 scenario (dashed lines)

according to the changes in the shape of the distributions. This was achieved by first determining the shifts in the cumulative distribution functions from the HIRHAM4 output (Fig. 3a) and then applying these changes to the observed distribution functions (Fig. 3b,c). Probability levels were used as a reference to assign specific anomalies to the individual years. Contrasting Fig. 3c with Fig. 2 shows that in CC differences in the probability density function between scenario and baseline are indeed in agreement with those simulated by HIRHAM4, but that the scenario also preserves the characteristics of the observed distributions.

Baseline climate and scenarios thus obtained for WAE are displayed in Fig. 4. The most striking differences between the $\mathrm{CM}$ and $\mathrm{CC}$ scenario are found in summer and winter precipitation, spring and autumn solar radiation, and summer temperature and humidity. While for some variables and months the CC scenario is characterized by a higher year-to-year variability, the opposite holds true when a narrowing of the distribution is indicated by the results of HIRHAM4.

\section{MODEL DESCRIPTION AND CALIBRATION}

CropSyst (version 3.04.01) is a process-based model that computes biomass accumulation and phenology at a daily time step for perennial and non-perennial crops specified by a generic set of parameters (Stöckle et al. 2003).

CropSyst is driven with daily values of solar radiation, maximum and minimum temperature, maximum and minimum relative humidity, wind speed, and precipitation. Daily biomass increment is calculated as the minimum of either an increment proportional to daily transpiration or an increment related to intercepted solar radiation. Phenological development is described
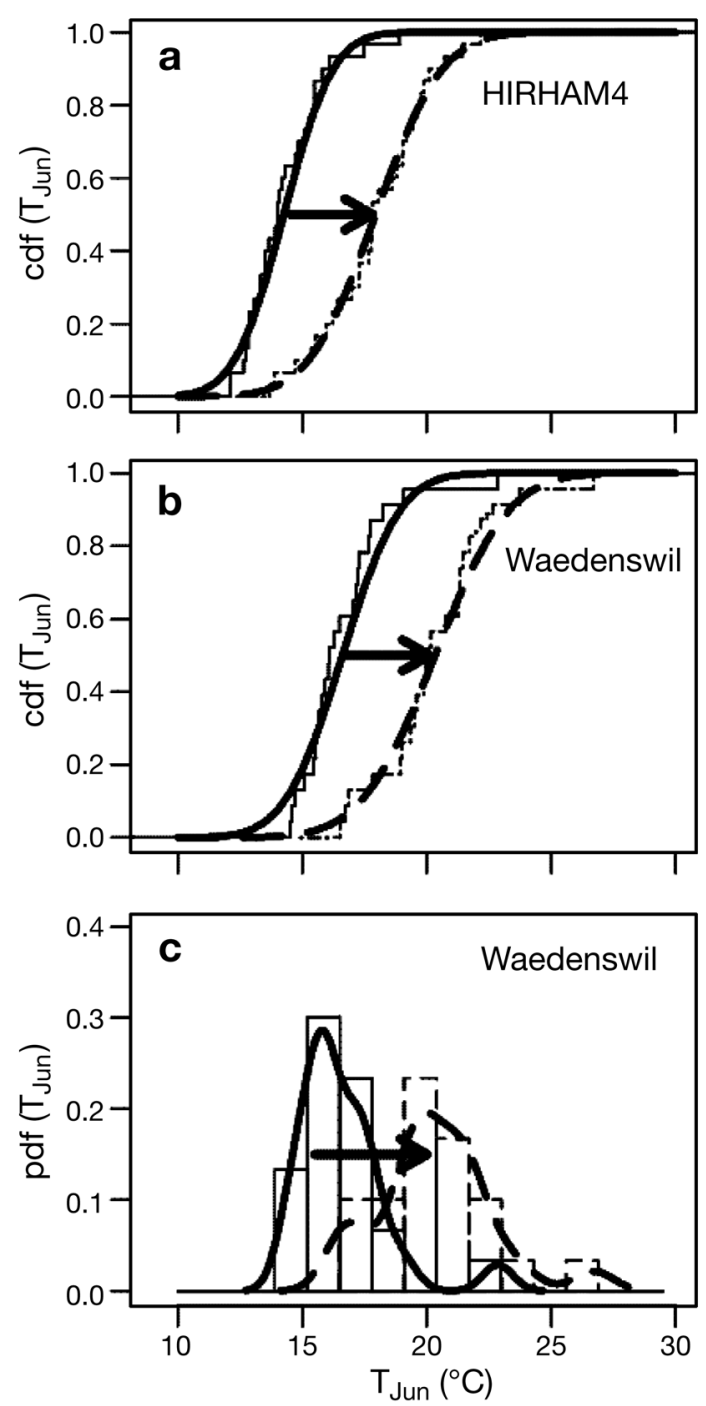

Fig. 3. Derivation of the CC climate change scenario for June monthly mean temperature. (a) Shift in the cumulative distribution function (cdf) simulated by HIRHAM4; application of changes to (b) the observed distribution function and (c) the probability density function (pdf). Continuous line = baseline; dashed line $=$ scenario

in terms of accumulated thermal units or growing degree days (GDD), and harvest is typically assumed to occur $5 \mathrm{~d}$ after maturity.

Plant processes are affected to various degrees by thermal and water stress, as well as by nutrient deficits. Atmospheric $\mathrm{CO}_{2}$ is assumed to affect both the canopy resistance (with implications for the daily transpiration) and the factors relating biomass accumulation to transpiration and intercepted solar radiation (Bristow \& Campbell 1984, C. Stöckle pers. comm.).

In our study, the model was calibrated with respect to the data obtained from 3 field trials: (1) 'Burgrain' (Dubois et al. 1999), a field experiment carried out in 

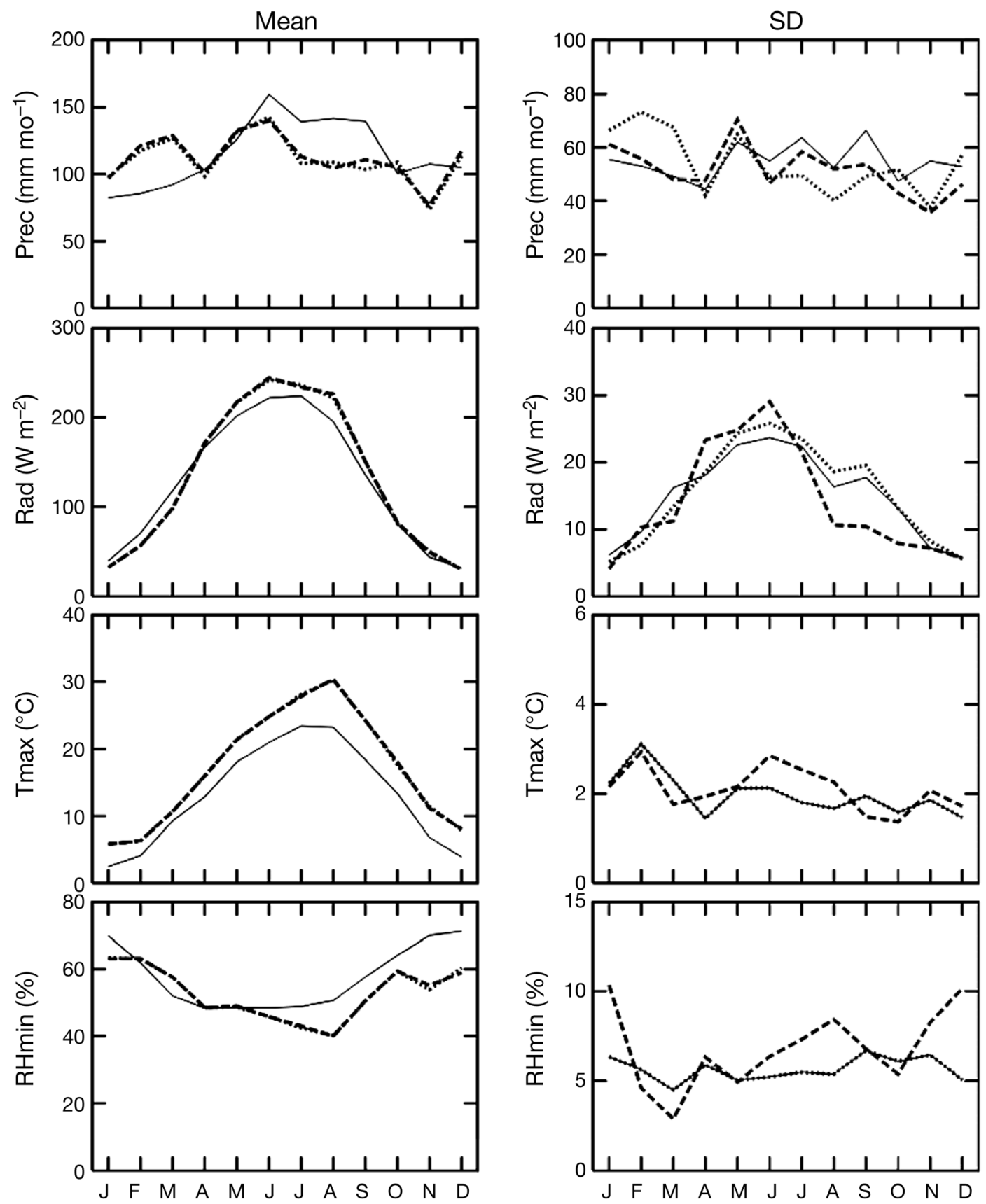

Fig. 4. Seasonal evolution of climatic characteristics at Waedenswil under present-day conditions (thin solid line) and in scenarios (thick dashed line = CC scenario; dotted line = CM scenario). (Dotted and dashed lines coincide in panels on the left-hand side; dotted and solid lines coincide in the lowermost 2 panels on the right-hand side.) Long-term mean and inter-annual SD are displayed in the left and right columns, respectively. From top to bottom: monthly total precipitation; monthly mean solar radiation; monthly mean maximum temperature; minimum relative humidity

1990 in central Switzerland that aimed to compare low input (organic), integrated and conventional management practices; (2) 'Chaiblen' (Dubois et al. 1998), a long-term field trial carried out in eastern Switzerland from 1989 to 1999 that investigated different rotations of wheat and maize and provided information on seeding date and density, variety, fertilizer and pesticide application, harvest date, and yield; and (3) a genotype testing and breeding program conducted from 1997 to 2003 in the region of Zurich, which provided detailed information on management practices, yield and chronology of phenological stages for canola and other winter cereals (Agroscope Reckenholz-Taenikon unpubl. data). 
Table 1. Zea mays (maize), Triticum spp. (winter wheat) and Brassica napus (winter canola). Crop parameters considered in the calibration and corresponding final values. GDD: growing degree days; ET: evapotranspiration;

AT/PT: ratio of actual to potential transpiration; LAI: leaf area index

\begin{tabular}{|lccc|}
\hline Parameter & Maize & $\begin{array}{c}\text { Winter } \\
\text { wheat }\end{array}$ & $\begin{array}{c}\text { Winter } \\
\text { canola }\end{array}$ \\
\hline Maximum root depth $(\mathrm{m})$ & & 1.5 & 1.25 \\
Harvest index $(-)$ & 1.5 & 0.48 & 0.45 \\
GDD for emergence $\left({ }^{\circ} \mathrm{C} \mathrm{d}\right)$ & 40 & 30 & 100 \\
GDD for flowering $\left({ }^{\circ} \mathrm{C} \mathrm{d}\right)$ & 700 & 1150 & 330 \\
GDD for leaf duration $\left({ }^{\circ} \mathrm{C}\right.$ d) & 1100 & 1300 & 1000 \\
GDD for grain filling $\left({ }^{\circ} \mathrm{C} \mathrm{d}\right)$ & 840 & 1300 & 450 \\
GDD for maturity $\left({ }^{\circ} \mathrm{C} \mathrm{d}\right)$ & 1250 & 1700 & 1200 \\
Base temperature $\left({ }^{\circ} \mathrm{C}\right)$ & 7 & 3 & 6 \\
Cut-off temperature $\left({ }^{\circ} \mathrm{C}\right)$ & 20 & 22 & 22 \\
Maximum leaf area index $(\mathrm{LAI})\left(\mathrm{m}^{2} \mathrm{~m}^{-2}\right)$ & 7 & 6 & 5 \\
Light to biomass conversion $\left(\mathrm{kg} \mathrm{MJ}^{-1}\right)$ & 3.6 & 3.5 & 1.5 \\
Light extinction coefficient $(-)$ & 0.45 & 0.48 & 0.45 \\
Transpiration to biomass coefficient $(\mathrm{kPa})$ & 7 & 5.8 & 8.4 \\
ET crop coefficient $(-)$ & 1.2 & 1.05 & 0.8 \\
AT/PT limiting leaf expansion $(-)$ & 0.95 & 0.95 & 0.8 \\
AT/PT limiting root expansion $(-)$ & 0.45 & 0.5 & 0.5 \\
Maximum water uptake $\left(\mathrm{mm} \mathrm{d}^{-1}\right)$ & 11 & 10 & 11 \\
Initial green LAI $\left(\mathrm{m}^{2} \mathrm{~m}{ }^{-2}\right)$ & 0.011 & 0.011 & 0.011 \\
Specific LAI $\left(\mathrm{m}^{2} \mathrm{~m}^{-2}\right)$ & 22 & 22 & 30 \\
Stem/leaf partitioning coefficient $(-)$ & 2.8 & 5 & 3 \\
Critical xylem water potential $\left(\mathrm{J} \mathrm{kg}^{-1}\right)$ & -1200 & -1300 & -1500 \\
Wilting xylem water potential $\left(\mathrm{J} \mathrm{kg}^{-1}\right)$ & -1800 & -2000 & -2500 \\
Phenological sensitivity to water stress $(-)$ & 1 & 1 & 1 \\
Biomass to grain translocation factor $(-)$ & 0.48 & 0.3 & 0.30 \\
\hline
\end{tabular}

Table 2. Zea mays (maize), Triticum spp. (winter wheat) and Brassica napus (winter canola). Observed and simulated dates of sowing and harvest as well as observed and simulated yields used as benchmark for calibrating CropSyst

\begin{tabular}{|lccccc|}
\hline \multirow{2}{*}{ Crop } & Sowing date & \multicolumn{2}{c}{ Harvest date } & \multicolumn{2}{c|}{ Yield $\left(\right.$ t ha $^{-1}$ ) } \\
& Obs. & Obs. & Sim. & Obs. & Sim. \\
\hline Maize $^{\mathrm{a}}$ & $\sim 4 \mathrm{May}$ & $\sim 30 \mathrm{Oct}^{\mathrm{b}}$ & $\sim 25 \mathrm{Oct}^{\mathrm{b}}$ & 7.8 & 7.8 \\
Winter wheat $^{\mathrm{a}, \mathrm{b}}$ & $\sim 10 \mathrm{Oct}$ & $\sim 3 \mathrm{Aug}$ & $\sim 9 \mathrm{Aug}$ & 6.8 & 6.1 \\
Winter canola $^{\mathrm{c}}$ & $\sim 5 \mathrm{Sep}$ & $\sim 17 \mathrm{Jul}$ & $\sim 27 \mathrm{Jul}$ & 3.0 & 2.8 \\
${ }^{\mathrm{a}}$ After Dubois et al. (1998); ${ }^{\mathrm{b}}$ after & Dubois et al. (1999); ${ }^{\mathrm{c}}$ canola cultivar \\
survey (Agroscope unpubl. data) & & & & \\
\hline
\end{tabular}

Daily weather data for the calibration were extracted from the database of MeteoSwiss for the following stations: (1) Lucerne (LUZ, $\left.47^{\circ} 0^{\prime} \mathrm{N}, 8^{\circ} 30^{\prime} \mathrm{E}\right)$; (2) Taenikon (TAE, $47^{\circ} 29^{\prime} \mathrm{N}, 8^{\circ} 54^{\prime} \mathrm{E}$ ); and (3) Zurich-Reckenholz (REH, $47^{\circ} 26^{\prime} \mathrm{N}, 08^{\circ} 31^{\prime} \mathrm{E}$ ) (Fig. 1).

The calibration was carried out in 2 steps, by adjusting first phenology and then biomass accumulation (van Ittersum et al. 2003). Critical crop parameters affected by the calibration are listed in Table 1, while Table 2 provides a summary of the benchmarks considered.

Not all of the relevant parameters could be specifically optimized. Owing to the lack of observations for leaf area index (LAI), the GDD necessary to reach maximum LAI were assumed to correspond to $95 \%$ of those required for flowering, whereas the GDD required for leaf duration were assumed to correspond to $90 \%$ of those required in order to reach maturity. This is in agreement with the standard settings of CropSyst. For wheat and canola, vernalization was adjusted to match observed dates of flowering. To drive vernalization, a crop parameter file provided by Istituto Sperimentale per le Colture Industriali (ISCI; M. Donatelli pers. comm.) was used.

For calibration and all subsequent simulations, a silty-clay soil was assumed (26\% sand, 38\% clay and 36\% silt), with a permanent wilting point at $0.21 \mathrm{~m}^{3} \mathrm{~m}^{-3}$, saturated hydraulic conductivity equal to $0.36 \mathrm{~m} \mathrm{~d}^{-1}$, air entry potential of $-2.39 \mathrm{~J}$ $\mathrm{kg}^{-1}$, and bulk density of $1.28 \mathrm{~g} \mathrm{~m}^{-3}$. A laboratory analysis of soil samples from the 'Burgrain' field trial (Dubois et al. 1999) suggested a soil organic matter content in the order of $2.6 \%$, which is higher than, but overall consistent with, the estimate of $1.5 \%$ determined by Leifeld et al. (2005) as an average value for the Swiss Plateau.

\section{RESULTS}

\subsection{Model testing}

The model was tested against farm census data collected since the early 1970s by the research station of the Swiss Federal Office for Agriculture located at Taenikon (ART 2002). The census refers to several thousand prototype farms spread over the Swiss territory (the exact number varies from year to year), which provide information on geographic location, cultivated area, crop yield and management costs, but not on seeding and harvest dates, nor rates of fertilizer applications.

Three regions were considered for the analysis. They were defined as the areas within a distance of $15 \mathrm{~km}$ from the 3 meteorological stations WAE, TAE and LUZ (see Sections $2 \& 3$ for coordinates). Census data from farms within these areas were aggregated and mean and SD were used for comparison with the simulations. The results are presented in Fig. 5, showing thatwith a few exceptions (in particular maize yield at WAE before 1985, and at TAE after 1987) — the model performance is satisfactory. Note that only the data up 

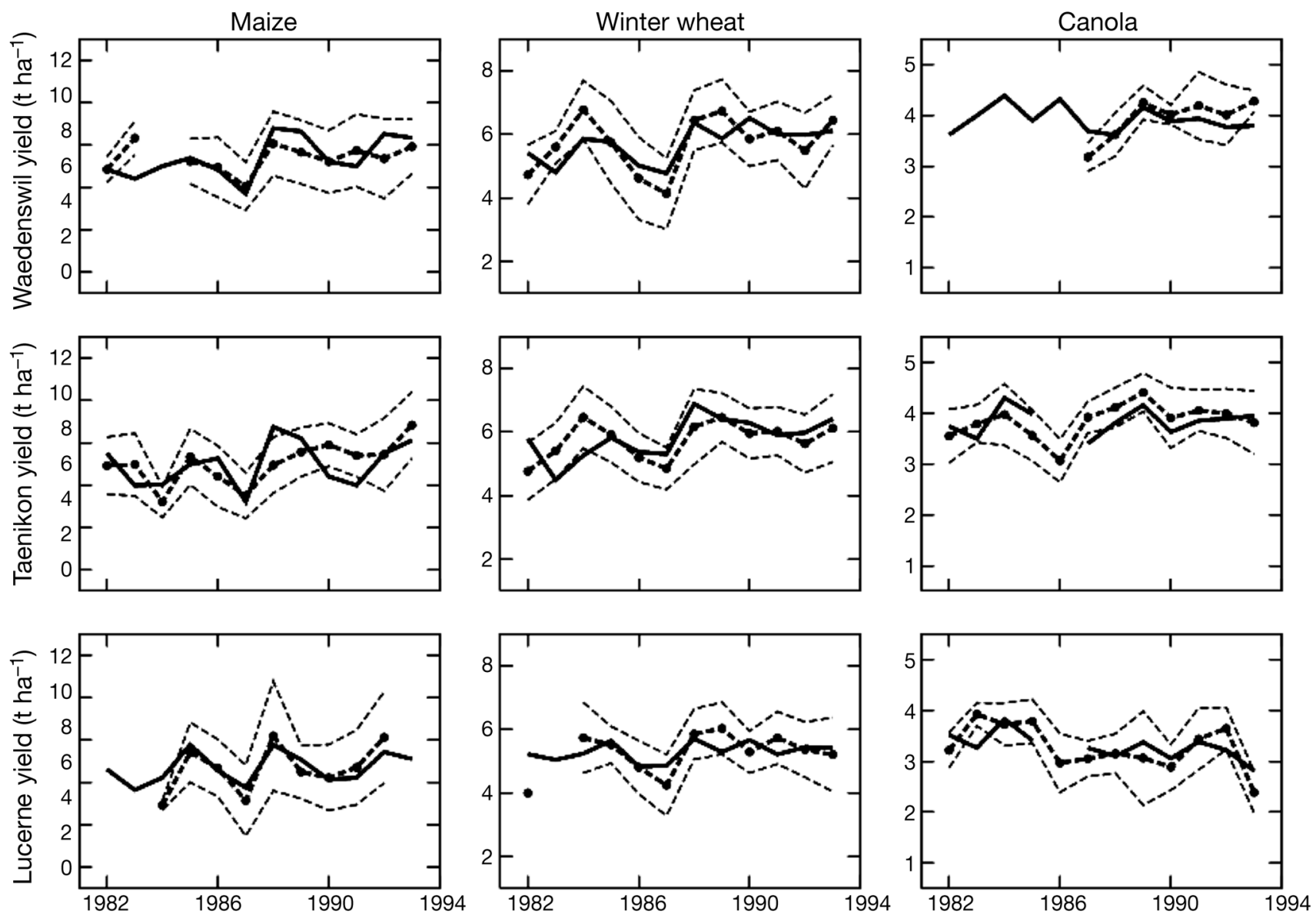

Fig. 5. Zea mays, Triticum spp. and Brassica napus (left to right). Comparison between simulated (solid line) and observed (dashed lines) yields for Waedenswil (top), Taenikon (middle) and Lucerne (bottom). Both mean (thick dashed line with dots) and range $( \pm 1 \mathrm{SD}$, thin dashed line) of the observations are depicted. Data cover the period 1982-1993. Note: number of observations varies depending on station, crop and year $(\min .=3$, max. $=38)$

to 1993 were retained, because a change in the agricultural practice from high-input to low-input management took place in that year.

\subsection{Effects of climate change and elevated $\mathrm{CO}_{2}$}

Results of simulations for rain-fed cropping that refer to current climatic conditions ('Baseline') and climate scenarios either without ('CM-', 'CC-') or including ('CM+', 'CC+') the effects of elevated $\mathrm{CO}_{2}$ concentrations are presented in Fig. 6.

For all 3 crops, climate change alone (CC-) resulted in a marked reduction in the median yield $(-34,-26$ and $-46 \%$ for maize, winter wheat and canola, respectively), and a substantial increase in the coefficient of yield variation $(\mathrm{CV})$ for maize and canola (+60 and $+130 \%$, respectively). In contrast, with regard to winter wheat, a decrease in the $\mathrm{CV}$ was simulated with the CC-scenario $(-30 \%)$.
With elevated $\mathrm{CO}_{2}(\mathrm{CC}+)$, median yields of maize and canola were still below the baseline level (-11 and $-12 \%$, respectively) and CVs were larger (+60 and $+180 \%$, respectively); however, for wheat, the median yield increased by $3 \%$ and the CV decreased by roughly $40 \%$.

Differences between the CM and CC simulations were systematic, but specific for each crop. For maize, the reduction in mean yield and the increase in the $\mathrm{CV}$ were less pronounced with respect to the CM than the CC scenario. For wheat, the shift in mean yield was larger and the increase in $\mathrm{CV}$ higher in the $\mathrm{CM}$ than in the $\mathrm{CC}$ simulation. A decrease in the $\mathrm{CV}$ was also indicated for canola, while a slight increase was observed for winter wheat. For both winter crops, phenology and biomass accumulation proved to be very sensitive to the climatic conditions of late autumn and early spring. For canola, unrealistic delays in development and yield deficits were simulated by CropSyst in 3 years. These were subsequently excluded from the analysis. 


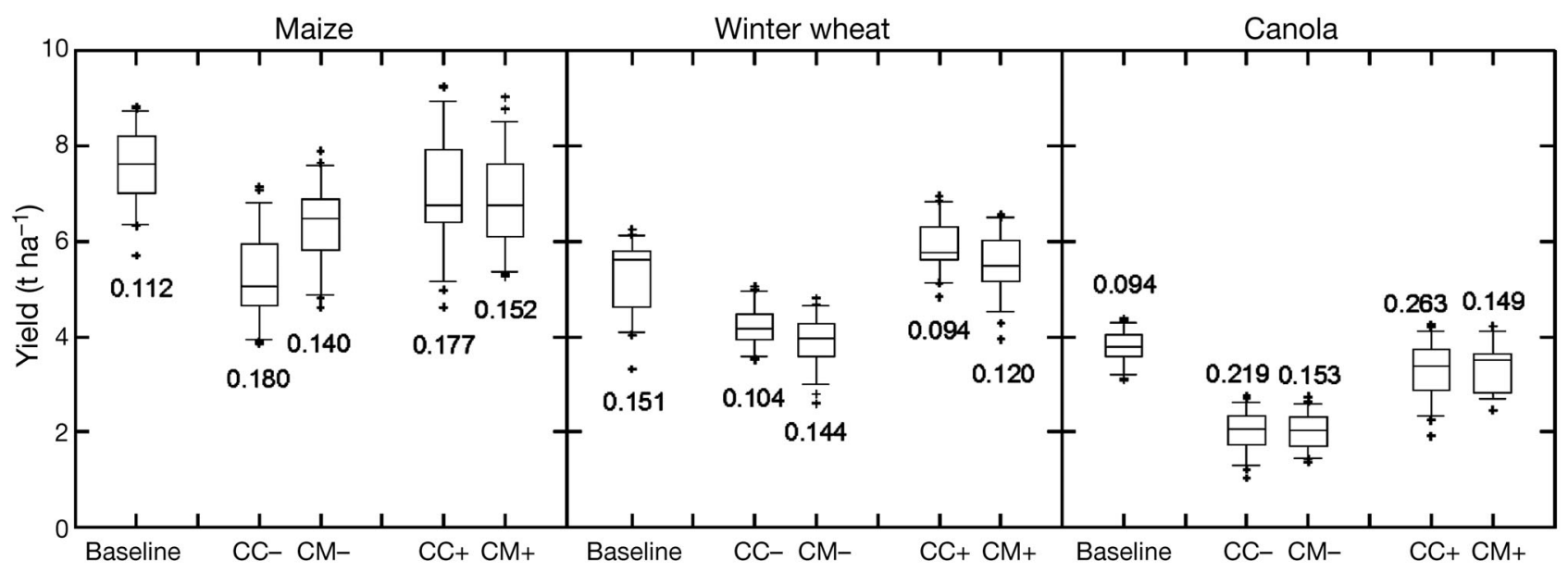

Fig. 6. Zea mays, Triticum spp. and Brassica napus (left to right). Simulated yields for baseline climate and climate change scenarios without (CC-) and with (CC+) elevated $\mathrm{CO}_{2}$ concentrations. Rain-fed cultivation is assumed. Numbers with box plots are $\mathrm{CV}$. Box plots show median (horizontal line), 25th and 75th percentiles (box), 10th and 90th percentiles (whiskers), and outliers (crosses)

Reduction in mean yield in the CM- and CC-simulations was associated with a shortening of the growing period, which was the consequence of increasing temperatures. If compared with the baseline, the length of the growing period (sowing to maturity) in the $\mathrm{CM} / \mathrm{CC}$ scenarios decreased from 131 to $105 / 105 \mathrm{~d}$ for maize, from 274 to $246 / 263 \mathrm{~d}$ for winter wheat and from 331 to 287/290 d for winter canola.

The effects of irrigation are only shown for maize (Fig. 7) because shortage of water in northern Switzerland effectively limits biomass accumulation only in summer and early autumn (Jasper et al. 2004), and is therefore irrelevant for the productivity of the 2 winter crops (not shown). As expected, irrigation increased yield and slightly improved yield stability. With irrigation, the reduction in median yield relative to the baseline was $23 \%$ in CC- (34\% in the rain-fed simulation),

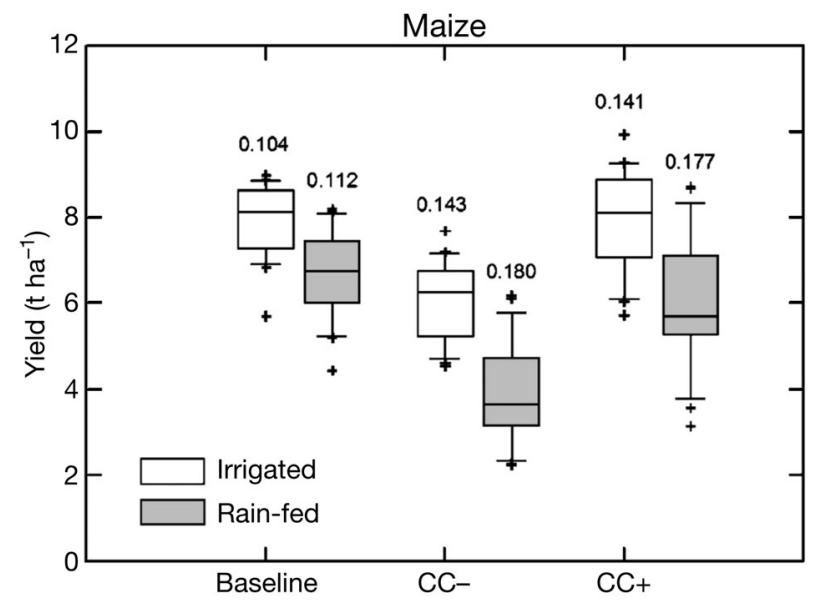

Fig. 7. Zea mays. Simulated yield under present-day (baseline) and future climatic conditions for rain-fed and irrigated cultivation. For scenarios and box plot details see Fig. 6 but baseline yield levels were maintained in the $\mathrm{CC}+$ simulation (reduced by $11 \%$ in the rain-fed simulation). With irrigation, CVs under climate change conditions were still considerably larger than in the baseline condition $(+38$ and $+36 \%$ in $\mathrm{CC}-$ and $\mathrm{CC}+$, respectively), but were nevertheless significantly smaller than in the rain-fed simulations.

\subsection{Sensitivity to GDD requirements}

Cultivars with differing thermal time requirements are already grown under current climatic conditions (Burton et al. 2004, Duvick 2005), and consideration of these differences could be one of the keys for developing effective measures of adaptation to climate change (Southworth et al. 2000).

The sensitivity of yield with respect to GDD requirements was examined by proportionally increasing the GDD thresholds given in Table 1 by +20 and $+40 \%$ (slower maturing cultivars). A proportional reduction by $10 \%$ in the GDD requirements was also examined to see whether a shortening of the growing season could prevent exposure to drought.

As seen in Fig. 8, median yield was indeed found to be highly sensitive to changes in GDD. A reduction in GDD by $10 \%$ resulted in lower median yield and increased CV for all 3 crops.

In contrast, higher GDD requirements had a positive impact on median yield. Under the assumption of a $40 \%$ increase in GDD, improvements relative to the $\mathrm{CC}+$ simulation were $+58,+33$ and $+75 \%$ for maize, wheat and canola, respectively. For canola, imposing higher thermal requirements also markedly reduced the CV of yield ( -55 and $-63 \%$ for the CC+ simulation of a GDD increase of 20 and $40 \%$, respectively). 


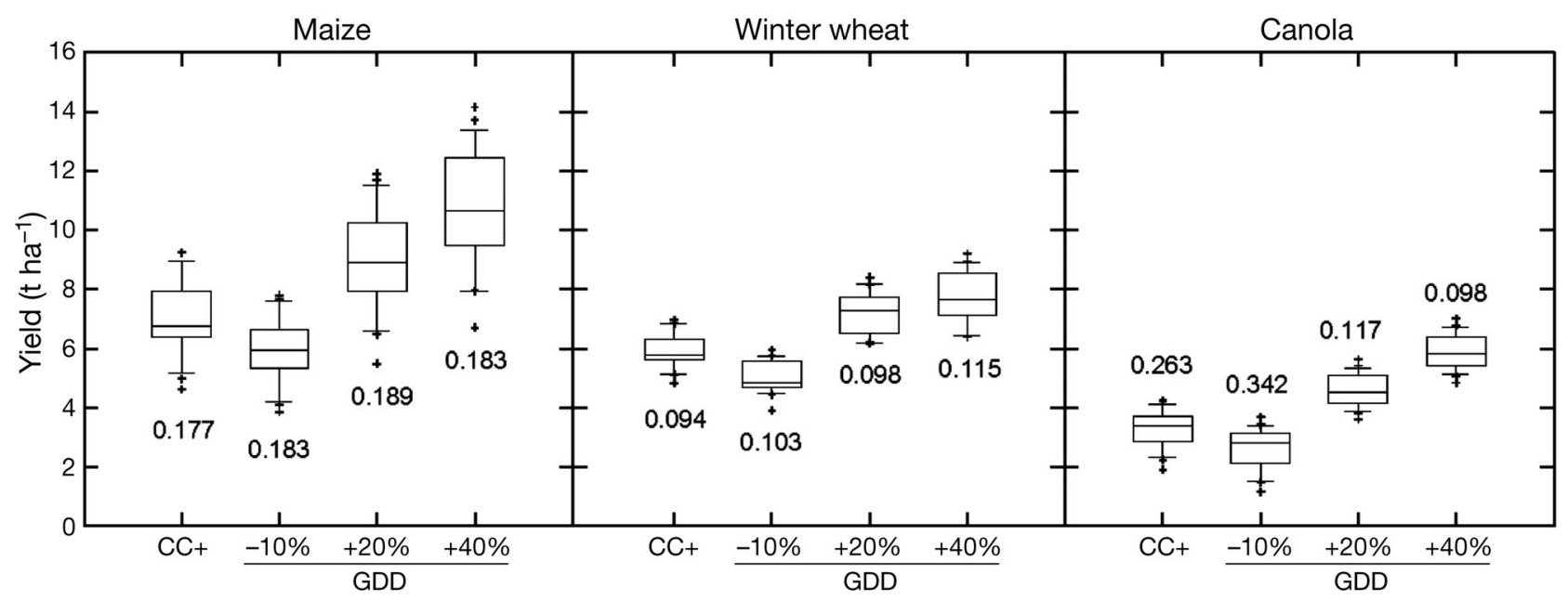

Fig. 8. Zea mays, Triticum spp. and Brassica napus (left to right). Effect of relative shifts in thermal time requirements (growing degree days, GDD) on mean yield and yield variability under climate change conditions. For box plot details see Fig. 6

\subsection{Sensitivity to sowing date and combined adjustments}

In the baseline simulations, sowing of maize, winter wheat and winter canola was prescribed on May 10, October 10 and August 25, respectively. The sensitivity of yield with respect to shifts in sowing date was examined in relation to the $\mathrm{CC}+$ scenario, with anticipations of 30 and $50 \mathrm{~d}$ in the case of maize (Fig. 9) and delays of 30 and $50 \mathrm{~d}$ in the case of winter wheat and winter canola (not shown). We speculated that a later sowing of winter crops could have some advantages with respect to the rotation of spring and winter crops, leaving a wider time window after the harvest of spring crops. However, the results of the simulations showed that the impact on yield was marginally (wheat) or considerably (canola) negative.

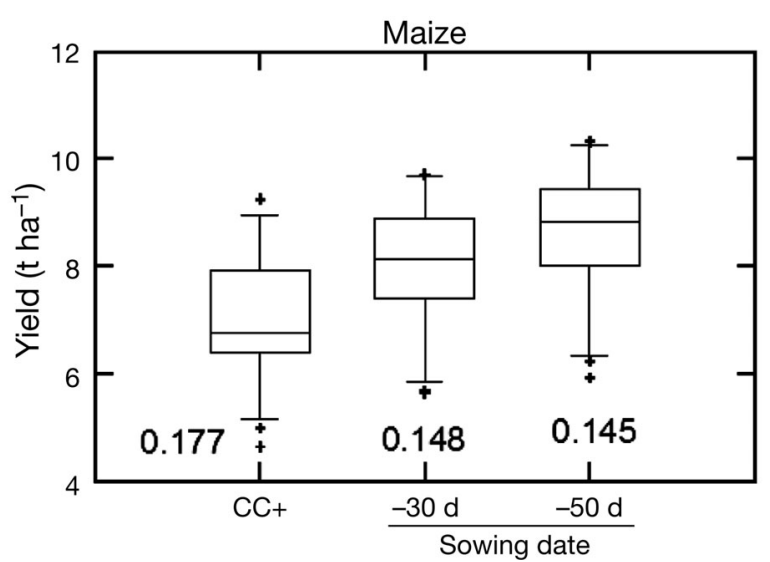

Fig. 9. Zea mays. Effect of shifts in sowing date on maize yield and yield variability under climate change conditions. For box plot details see Fig. 6
For maize, the anticipation of the sowing date had beneficial impacts on yield and yield stability, reducing the coefficient of yield variation by roughly $20 \%$ relative to the simulation with standard sowing date.

In view of the above results, we also considered a combination of adjustments for maize. The effects of increased GDD and earlier date of sowing are illustrated in Fig. 10 as a plot of mean yield vs. SD. Mean yield and yield variability were to a high degree determined by changes in the GDD. A positive effect of earlier sowing date on yield stability could only be detected in combination with a moderate increase in the GDD requirements.

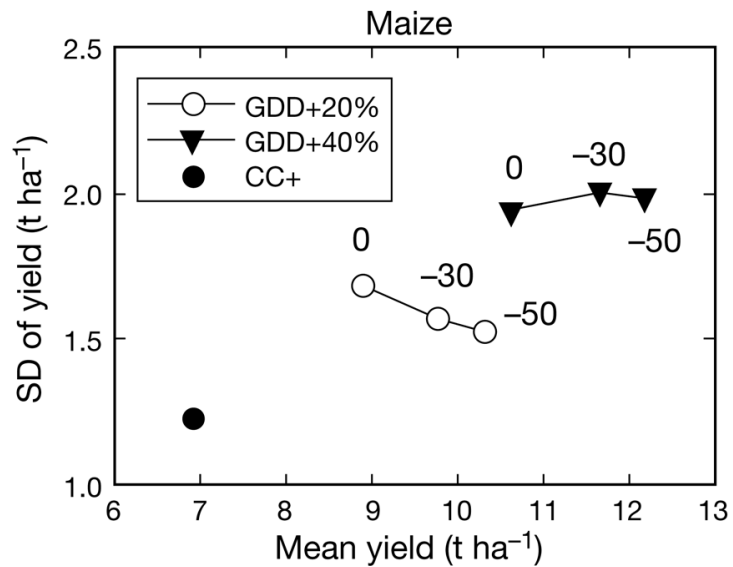

Fig. 10. Zea mays. Combined effect of an increase in growing degree day (GDD) requirements and an anticipation of the sowing date, under climate change conditions and elevated $\mathrm{CO}_{2}$ concentrations, on maize yield and yield variability. Changes in GDD (+20 and $+40 \%$ ) are relative to the baseline. Anticipation of the sowing date $(0,-30$ and $-50 \mathrm{~d})$ is given next to the symbols. Result of CC+ scenario without GDD modification 


\section{DISCUSSION}

Elevated $\mathrm{CO}_{2}$ concentrations and global warming are expected to amplify the inter-annual variability of summer climate in central and eastern Europe (Beniston \& Diaz 2004). Climatic conditions in these areas thus become comparable with those in the Mediterranean basin, which implies increasing risks to yield of spring crops during the course of the 21st century (Olesen \& Bindi 2002, Porter \& Semenov 2005, Fuhrer et al. 2006).

While the importance of taking into account changes in climate variability when deriving regional climate scenarios is beyond question (Mearns et al. 1997), there is actually no unique approach by which to do so. Use of weather generators can be recommended when historical weather records are of sufficient length to achieve a realistic and reliable conditioning of the statistical models implemented in the generators. In comparison, the adjustment of observed weather data with anomalies derived from simulations with climate models (Houghton et al. 2001) has the advantage of being straightforward and able to accommodate biases in the model output, which are substantial in relation to the precipitation field over the Alpine region (Frei et al. 2003).

Here we propose a simple method for developing unbiased climate scenarios, whereby observed daily data are adjusted with monthly anomalies that reflect the full changes in the probability distribution of each of the climatic elements. The method preserves the relationships between precipitation on the one hand, and solar radiation, temperature and air humidity on the other hand. This is a strict requirement for the simulation of climate change impacts on crop productivity.

The main weakness of the proposed procedure is that it does not take into account day-to-day changes in weather patterns. This also means that the frequency of rainfall events is left unchanged. Shifts in the occurrence of rainfall can be as important as changes in rainfall intensity (Calanca 2006); simultaneous frequency and intensity correction of modelled daily rainfall was recently explored by Ines \& Hansen (2006).

With respect to mean climate, the main features of the CC scenario developed for this study were an increase/decrease in winter/summer precipitation, an increase in solar radiation in spring and summer, a systematic increase in air temperature, and a decrease in air humidity in summer and autumn. These characteristics were in general agreement with projections from an ensemble of scenarios used in an earlier study (Jasper et al. 2004). But unlike in these earlier scenarios, we only observed a slight decrease in the variability of summer precipitation, an increase/decrease in the variability of solar radiation in spring/late summer, and a substantial increase in both the variability of temperature and humidity during summer.

Overall, the impact of the scenario on the simulated yield of maize, winter wheat and winter canola was to lower the mean productivity and, for maize and canola, to induce a greater year-to-year variability. The negative impact of $\mathrm{CC}$ was striking when the effects of elevated $\mathrm{CO}_{2}$ concentrations (scenario $\mathrm{CC}-$ ) were ignored, and less pronounced when $\mathrm{CO}_{2}$ stimulation of crop growth $(\mathrm{CC}+)$ was considered. However, this latter result needs to be verified in the future. As in other crop models, the parameterization of the $\mathrm{CO}_{2}$ effects in CropSyst was originally inferred from data reported by Kimball (1983). Conclusions drawn from the data were recently questioned by Long et al. (2006), who reviewed the findings from more recent free-air concentration enrichment (FACE) experiments.

Systematic differences were found between CC and $\mathrm{CM}$ simulations, emphasizing the importance of yearto-year variations in the climate settings. These differences were crop-specific, with dissimilarities not only in the response of spring and winter crops, but also in the response of the 2 winter crops considered. This means that conclusions on the impact of climate change on crop productivity drawn for a particular crop cannot be extended to other crops (see also Porter \& Semenov 2005).

In our model study, the negative effects of climate change were mainly associated with the impacts of higher temperatures on phenology, namely the acceleration of crop development (Porter 2005). Estimates for the reduction in the length of the grain-filling period are currently set between 1 and $2 \mathrm{~d}$ per $1^{\circ} \mathrm{C}$ increase (Olesen 2005), whereas estimates for the advancement of maturity dates are given in the order of $1 \mathrm{mo}$ per $4^{\circ} \mathrm{C}$ increase in mean temperature (Tubiello et al. 2000). In our simulations, the shortening of the growing period was significant for all crops. A higher incidence of water stress was also indicated for maize.

The $8 \%$ reduction in mean yield of maize in response to $\mathrm{CC}+$ compares well with results from 2 Italian locations (-13\%, Tubiello et al. 2000), even though our simulation did not account for the negative impact of heat stress on maize fertility (Challinor et al. 2005). As suggested in Fig. 7, current levels of productivity of spring crops can effectively be maintained through irrigation.

The above discussion applies to the unrealistic situation of no change in crop management in response to new climatic conditions. Options for autonomous adaptation exist and should be further explored in the future (Olesen \& Bindi 2002). Because growth and yield are contingent on the duration of phenological phases (Horie 1994), increasing the GDD requirements 
in the simulations was the simplest way by which to mimic slower maturing cultivars that could be obtained through genetic improvement (Duvick 2005). The simulations indicated that an increase in GDD requirements is highly effective in overcoming the negative effects of CC: resulting yields clearly exceeded baseline levels for all crops. However, increasing the GDD requirements may not necessarily improve yield stability: for maize and wheat (but not canola), the simulated increase in mean yield was associated with a larger $\mathrm{CV}$.

The other simple, possible adaptation to the new climatic conditions that we explored in our study was a shift in the planting dates to allow crop development during more favourable conditions, i.e. earlier sowing of spring-sown crops and later sowing of winter cereals. The simulations showed that advancing the sowing date is an effective measure by which to counteract CC with respect to spring or summer crops. However, delaying the planting date for winter crops made it difficult to obtain a realistic phenology and plant development.

Several important issues could not be addressed in our investigation. For instance, field studies have shown that a modification of the activity of plant diseases and weeds resulting from shifts in sowing date can be relevant for quantity and quality of grain yield (Kirby et al. 1984, Hossain et al. 2003). These and other aspects should be included in an extension of the present study.

\section{CONCLUSIONS}

In this study, a simple method was proposed for deriving unbiased climate scenarios from the output of climate models. Application of the scenarios to the analysis of crop yield confirmed the differential sensitivity of crops to climate change. Of the 3 crops studied, winter wheat was the only one to respond positively to climate change in combination with elevated $\mathrm{CO}_{2}$. Without $\mathrm{CO}_{2}$ fertilization, the average impact of climate change on harvestable yield was consistently negative.

The results proved to be sensitive to the choice of seeding date and thermal time requirement. For maize, a combination of simple measures of adaptation was effective in overcoming the negative effects of climate change; however, for the winter crops, improvements could only be simulated with respect to an increase in the GDD requirements. These results suggest that there is no general rule for adapting different crops to new climatic conditions.

Our study focused on the north area of Switzerland. Experiments with regional and global climate models are in agreement in indicating a transition from a temperate to a more arid summer climate in this region during the coming decades. The implications of these changes, which we simulated with CropSyst for maize, were consistent with those of previous studies. Less certain are our conclusions with respect to winter crops. This is partly owing to difficulties that remain in correctly reproducing the phenology, leaf-area development and yield of winter crops. In this respect, improvement of the model behaviour is a necessary step toward a more reliable assessment of the impact of climate change on cropping systems.

Acknowledgements. This study was supported by the Swiss National Science Foundation within the framework of the National Competence Centre on Research in Climate (NCCR Climate). We thank the Swiss Federal Office of Meteorology and Climatology (MeteoSwiss) for providing access to its database; Prof. C. Stöckle for the internship at Washington State University, and Dr. M. Donatelli from the Istituto Sperimentale per le Colture Industriali for providing the reference crop file for canola.

\section{LITERATURE CITED}

ART (Agroscope Reckenholz-Tänikon) (2002) Ergebnisse der Zentralen Auswertung von Buchhaltungsdaten. Research Station Agroscope Reckenholz-Taenikon, Ettenhausen

Beniston M, Diaz HF (2004) The 2003 heat wave as an example of summers in a greenhouse climate? Observations and climate model simulations for Basel, Switzerland. Global Planet Change 44:73-81

Bristow RL, Campbell GS (1984) On the relationship between incoming solar radiation and daily maximum and minimum temperature. Agric For Meteorol 31:159-166

Burton WA, Ripley VL, Potts DA, Salisbury PA (2004) Assessment of genetic diversity in selected breeding lines and cultivars of canola quality Brassica juncea and their implications for canola breeding. Euphytica 136:181-192

Calanca P (2006) Climate change and drought occurrence in the Alpine region: how severe are becoming the extremes? Global Planet Change doi:10.1016/j.gloplacha. 2006.11.001

Calderini DF, Slafer GF (1998) Changes in yield and yield stability in wheat during the 20th century. Field Crops Res 57:335-347

Challinor AJ, Wheeler TR, Slingo JM (2005) Simulation of the impact of high temperature stress on yield of an annual crop. Agric For Meteorol 135:180-189

Chloupek O, Hrstkova P, Schweigert P (2004) Yield and its stability, crop diversity, adaptability and response to climate change, weather and fertilization over 75 years in the Czech Republic in comparison to some European countries. Field Crops Res 85:167-190

Christensen JH, Carter TR, Giorgi F (2002) PRUDENCE employs new methods to assess European climate change. EOS 83:147

Christensen OB, Christensen JH, Machenauer B, Botzet M (1998) Very high-resolution regional climate simulations over Scandinavia - present climate. J Clim 11:3204-3229

Dubois D, Scherrer C, Gunst L, Jossi W, Stauffer W (1998) Auswirkungen verschiedener Landbauformen auf den Bodenvorrat an Unkrautsamen in den Langzeitversuchen 
Chaiblen und DOK. Z Pflanz Krankh Pflanzensch Sonderh XVI:67-74

Dubois D, Zihlmann U, Fried PM (1999) Burgrain: Erträge und Wirtschaftlichkeit dreier Anbausysteme. Agrarforschung 6:169-172

Duvick DN (2005) The contribution of breeding to yield advances in maize (Zea mays L.). Adv Agron 86:83-145

Frei C, Christensen JH, Déqué M, Jacob D, Jones RG, Vidale PL (2003) Daily precipitation statistics in regional climate models: evaluation and intercomparison for the European Alps. J Geophys Res 108:4125, doi:10.1029/2002JD002287

Fuhrer J (2003) Agroecosystem responses to combinations of elevated $\mathrm{CO}_{2}$, ozone, and global climate change. Agric Ecosyst Environ 97:1-20

Fuhrer J, Beniston M, Fischlin A, Frei C, Goyette S, Jasper K, Pfister C (2006) Climate risks and their impact on agriculture and forests in Switzerland. Clim Change 79:79-102

Horie T (1994) Crop ontogeny and development. In: Boote KJ, Bennett JM, Sinclair TR, Paulson GM (eds) Physiology and determination of crop yield. ASA/CSSA/SSSA, Madison, WI, p 153-180

Hossain I, Epplin M, Krenzer EG Jr (2003) Planting date influence on dual-purpose winter wheat forage yield, grain yield, and test weight. Agron J 95:1179-1188

Houghton JT, Ding Y, Griggs DJ, Noguer M, van der Linden PJ, Dai X, Maskell K, Johnson CA (2001) Climate change 2001: the scientific basis. Contribution of Working Group I to the Third Assessment Report of the Intergovernmental Panel on Climate Change. Cambridge University Press, Cambridge

Ines AVM, Hansen JW (2006) Bias correction of daily GCM rainfall for crop simulation studies. Agric For Meteorol 138:44-53

Jasper K, Calanca P, Fuhrer J (2004) Differential impacts of climate change on the hydrology of two alpine river basins. Clim Res 26:113-129

Johns TC, Gregory JM, Ingram WJ, Johnson CE and 8 others (2003) Anthropogenic climate change for 1860 to 2100 simulated with the HadCM3 model under updated emissions scenarios. Clim Dyn 20:583-612

Kimball BA (1983) Carbon-dioxide and agricultural yield. An assemblage and analysis of 430 prior observations. Agron J 75:779-788

Kirby EJM, Appleyard M, Fellowes G (1984) Variation in development of wheat and barley in response to sowing date and variety. J Agric Sci 104:382-396

Leifeld J, Bassin S, Fuhrer J (2005) Carbon stocks in Swiss agricultural soils predicted by land-use, soil characteristics and altitude. Agric Ecosyst Environ 105:255-266

Long SP, Ainsworth EA, Rogers A, Ort DR (2004) Rising atmospheric carbon dioxide: plants FACE the future. Annu Rev Plant Biol 55:591-628

Editorial responsibility: Helmut Mayer, Freiburg, Germany
Long SP, Ainsworth EA, Leakey ADB, Nösberger J, Ort DR (2006) Food for though: lower-than-expected crop yield stimulation with rising $\mathrm{CO}_{2}$ concentrations. Science 312: 1918-1921

Mearns LO, Rosenzweig C, Goldberg R (1997) Mean and variance change in climate scenarios: methods, agricultural applications, and measures of uncertainty. Clim Change 35:367-396

Nakicenovic N, Swart R (2000) Special report on emission scenarios: a special report of Working Group III of the Intergovernmental Panel on Climate Change. Cambridge University Press, Cambridge

Olesen JE (2005) Climate change and $\mathrm{CO}_{2}$ effects on productivity of Danish agricultural systems. J Crop Improv 13: $257-274$

Olesen JE, Bindi M (2002) Consequences of climate change for European agricultural productivity, land use and policy. Eur J Agron 16:239-262

Pope DV, Galliani M, Rowntree R, Stratton A (2000) The impact of new physical parametrizations in the Hadley Centre climate model HadAM3. Clim Dyn 16:123-146

Porter JR (2005) Rising temperatures are likely to reduce crop yields. Nature 436:174

Porter JR, Semenov MA (2005) Crop responses to climatic variation. Philos Trans R Soc Lond B 360:2021-2035

Räsisänen J (2002) $\mathrm{CO}_{2}$-induced changes in interannual temperature and precipitation variability in 19 CMIP2 experiments. J Clim 15:2395-2411

Rosenzweig C, Iglesias A (2000) Climate change and US agriculture: the impact of warming and extreme weather events on productivity, plant diseases, and pests. Harvard University, Cambridge, MA

Sombroek W, Bazzaz F (1996) The climate change-agriculture conundrum. In: Bazzaz F, Sombroek W (eds) Global climate change and agricultural production. FAO, Rome, p 1-14

Southworth J, Randolph JC, Habeck M, Doering OC, Pfeifer RA, Rao DG, Johnston JJ (2000) Consequences of future climate change and changing climate variability on maize yields in the midwestern United States. Agric Ecosyst Environ 82:139-158

Stöckle CO, Donatelli M, Nelson R (2003) CropSyst, a cropping system simulation model. Eur J Agron 18: 289-307

Tubiello FN, Donatelli M, Rosenzweig C, Stockle CO (2000) Effects of climate change and elevated $\mathrm{CO}_{2}$ on cropping systems: model predictions at two Italian locations. Eur J Agron 12:179-189

van Ittersum MK, Leffelaar PA, van Keulen $H$, Kropff MJ, Bastiaans L, Goudriaan J (2003) On approaches and application of the Wageningen crop models. Eur J Agron 18: 201-234

Submitted: October 2, 2006; Accepted: February 6, 2007

Proofs received from author(s): April 26, 2007 